AJChE 2016, Vol. 16, No. 2, 59 - 69

\title{
Making of Nanopore NaA Zeolite Membranes for Saline Wastewater Treatment
}

\author{
Mansoor Kazemimoghadam *,1 \\ 1 Malek Ashtar University of Technology, Faculty of Chemical and Chemical Engineering, \\ Tehran, Iran \\ *e-mail: mzkazemi@gmail.com
}

Zeolite membranes have been studied extensively for more than fifteen years, mainly focusing on gas separation and liquid pervaporation processes. Recently, molecular dynamic simulation has shown that zeolite membranes are theoretically suitable for ion removal from aqueous solutions. This work proposes to use zeolite membranes for desalination of saline recycled wastewater for the possibility of avoiding the costly treatment needed for saline wastewater by Conventional approaches. NaA zeolite membrane indicates that it may be possible to simultaneously separate ions and dissolved organic compounds from water by pervaporation (PV) processes. NaA zeolite membranes composed of a continuous intergrowth of $\mathrm{NaA}$ zeolite crystals have been prepared hydro thermally on the surface of porous tubular supports. In this research, synthesis of zeolite NaA membrane was investigated. SEM and XRD analysis have been used to confirm zeolite $\mathrm{NaA}$ membrane formation. Membrane performance has been evaluated using an experimental pervaporation setup. Effects of operation condition (temperature, rate and pressure) on the membrane structure and performance have been investigated for $\mathrm{NaA}$ zeolite membranes grown onto seeded mullite supports.

Keywords: Nanopore, NaA zeolite membrane, Pervaporation, Wastewater

\section{INTRODUCTION}

The supplies of potable water available to communities in worldwide have been depleted. Major initiatives are under way to find engineering solutions to improve potable water supply such as conservation, recycling and desalination (Colomer 2006). To effectively reduce the risk of major water supply shortages, each must be implemented. Desalination technology has been pursued for over 100 years and works by selectively taking the fresh water from non-potable saline sources typically in high abundance such as brackish or seawater. Mature systems are already in existence, for example in the Middle East, which either use distillation or more recently, reverse osmosis (RO) using polymeric membranes (Almutairi 2015). Zeolite membranes may be used as an alternative to polymeric membranes for desalination of complex wastewaters, which contain organic solvents and radioactive elements, or when high temperature operation is desired. Zeolites are microporous aluminosilicate crystalline materials that have been widely used as 
adsorbents for gas and liquid separations due to their extremely uniform pore sizes and unique surface properties. RO desalination using zeolite membranes may offer an alternative for some difficult water treatment processes such as concentration of low-level radioactive wastewater and desalination of high-concentration organic water produced in oil and gas operations where the conventional technologies, including polymeric RO membranes, are either inapplicable or inefficient, due to severe fouling and material instability (Premakshi et al. 2015).

To further develop RO using zeolite membranes, it is necessary to investigate mechanisms of ion and water transport in real membranes and fabricate defect-free membranes. Therefore, experimental investigation about zeolite membrane preparation is necessary. Recently, molecular dynamic simulation has shown that zeolite membranes are theoretically suitable for ion removal from aqueous solutions by RO. Results of the simulation showed complete rejection of sodium ions due to size exclusion of the hydrated ions with sizes much larger than the zeolitic pore sizes.

To be suitable to remove salt ions from aqueous solutions, the zeolite pore size and intercrystalline interconnections should be well below the size of hydrated salt ions. The aperture size of the $\mathrm{NaA}$ zeolite is approximately $0.4 \mathrm{~nm}$, which theoretically meets the criteria as mentioned above for selective separation of water (kinetic diameter $0.276 \mathrm{~nm}$ ) from hydrated salt ions. In addition, the $\mathrm{NaA}$ type zeolite membranes had great potential for separation of dissolved organics from aqueous solution. Porous inorganic membranes such as zeolites provide a rigid ceramic structure suitable for separating the small water molecules from larger salt ions, for example the hydrated size of $\mathrm{Na}^{+}$and $\mathrm{Cl}^{-}$ions being 0.72 and $0.66 \mathrm{~nm}$, respectively. Desalination with inorganic membranes is a novel application. Common desalination RO systems require high pressures, with plants typically operated in the order of $\mathrm{MPa}$ to overcome the osmotic force to drive membranes to separation mode. Hydrated ions size is shown in Table 1.

Table 1. Hydrated lons Size

\begin{tabular}{cc}
\hline Ion & Hydrated Diameter \\
\hline $\mathrm{H}_{2} \mathrm{O}$ & $0.56 \mathrm{~nm}$ \\
$\mathrm{Li}^{+}$ & $0.76 \mathrm{~nm}$ \\
$\mathrm{Na}^{+}$ & $0.72 \mathrm{~nm}$ \\
$\mathrm{~K}^{+}$ & $0.66 \mathrm{~nm}$ \\
$\mathrm{Mg}^{++}$ & $0.86 \mathrm{~nm}$ \\
$\mathrm{Ca}^{++}$ & $0.82 \mathrm{~nm}$ \\
$\mathrm{OH}^{-}$ & $0.60 \mathrm{~nm}$ \\
$\mathrm{Cl}^{-}$ & $0.66 \mathrm{~nm}$ \\
$\mathrm{NO}_{3}{ }^{-}$ & $0.68 \mathrm{~nm}$ \\
\hline
\end{tabular}

With the increasing of industrial wastewater discharge standards, especially in some environmentally sensitive areas, the "zero discharge" environmental standard should be implemented strictly to reuse wastewater in maximum extent. In such situation, the treatment of saline wastewater is gradually getting people's attention. This study has therefore investigated feasibility of using membranes in wastewater treatment. Recycling of treated wastewater is a key approach in a sustainable water management in the world to minimize the growing water demand in a water scarce 
environment. In addition, treated wastewater could possibly be reused for various purposes such as agricultural irrigation, landscape irrigation, industrial recycling, stream flow augmentation, and non-potable reuse. Therefore, the organic pollutants and high salt concentrations in wastewater must be removed ( Zhu et al. 2015). The polymer membranes have fouling problems and will degrade when exposed to extreme acidic, alkaline, or oxidizing environments. Apart from these, the lifespan of the polymer membranes will also be shortened when used in a harsher environment with more abrasive particles due to their low abrasionresistant ability. Ceramic membranes made from zeolites have been studied for gas and liquid separations, and membrane reactors due to their high separation performance, good catalytic activity, and high thermal, chemical and mechanical stability as well as chemical and solvent resistance. The zeolite membranes are promising candidates for desalination of saline water including seawater, as they possess the nanoporous structure required to remove ions from aqueous saline solutions. Therefore, they may be used for treatment of complex wastewater containing organic solvents and saline wastewater. UDMH is an important solvent; however, it also finds many new applications as an oxygen scavenger for boiler-feed water, a starting material for drug and dye intermediates, a catalyst for polymerization reactions, etc. UDMH is produced by the Rashing process, which involves reaction of ammonia with sodium hypochloride to give chloramines, which in turn are reacted with dimethylamine to obtain UDMH. Its wastewater contains low concentrations of UDMH (<2 wt. \%) besides impurities such as sodium chloride salt ( $8 \%)$ and water (>90\%). Conventional purification methods, which involve flash vaporization followed by extractive distillation, are highly energy-intensive and about $210 \mathrm{~kg}$ of steam is required to obtain $1 \mathrm{~kg}$ of UDMH. In addition, this method is very hazardous since UDMH is highly flammable and forms explosive mixtures with air. Moreover, UDMH is very corrosive and its vapor is extremely toxic and carcinogenic (Malekpour et al. 2008). Therefore, the search for a safer and more economical alternative technology is a challenging problem. In this research, preparation method of $\mathrm{NaA}$ nanopore zeolite membranes on mullite supports is reported. We adapt the pervaporation technique to operate nanopore $\mathrm{NaA}$ zeolite membranes for water recovery by desalination and organic removal from UDMH wastewater and effect of various operation conditions such as feed pressure, temperature and rate on water flux to understand optimal operating conditions.

\section{HYDRATED IONS SIZE IN WATER}

Porous inorganic membranes such as zeolites provide a rigid ceramic structure suitable for separating the small water molecules $(0.26 \mathrm{~nm})$ from larger salt ions, for example the hydrated size of $\mathrm{Na}+$ and $\mathrm{Cl}^{-}$ions being 0.72 and $0.66 \mathrm{~nm}$, respectively. Zeolite membranes show promise for desalination because of their ordered inorganic structures. Desalination 


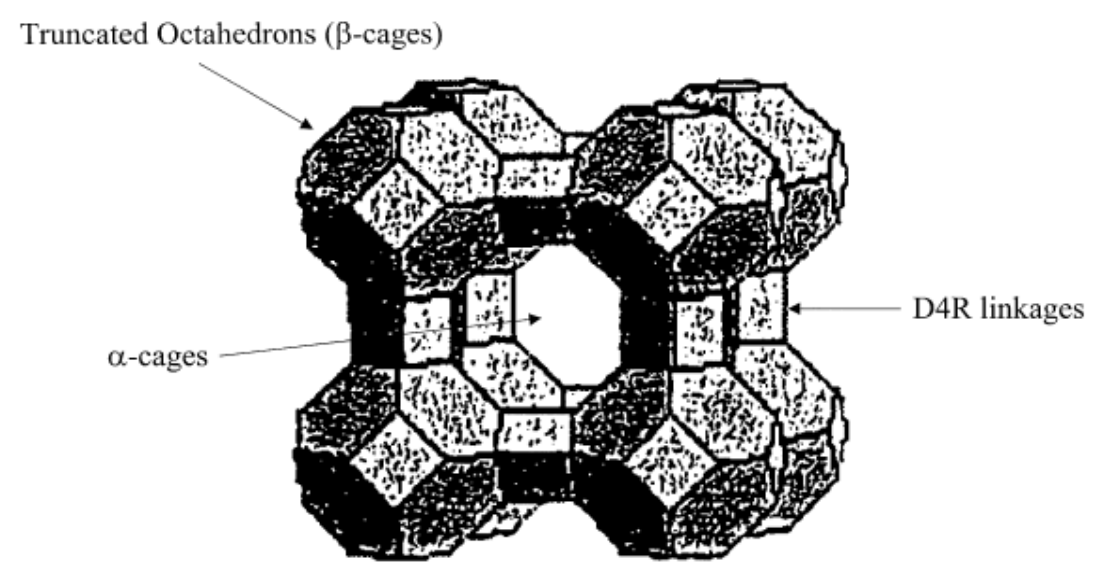

Fig. 1: Repeating Unit of Zeolite $\mathrm{NaA}$

with inorganic membranes is a novel application. The nonvolatile dissolved solids mean traditional pervaporation used already for alcohol dewatering is not effective. Common desalination RO systems require high pressures, with plants typically operated in the order of MPa to overcome the osmotic force to drive membranes to separation mode. Hydrated ions size is shown in table 1 (Gazagnes et al. 2007).

\section{ZEOLITE STRUCTURE AND TRANSPORT MECHANISMS}

The hydrophilic membranes used in this research were composite zeolite $\mathrm{NaA}$ membranes. The membranes were made of an active $\mathrm{NaA}$ layer, deposited on a ceramic porous mullite support. The active $\mathrm{NaA}$ layer is responsible for high flux achieved in PV process. The structure of zeolite $\mathrm{NaA}$ is shown in Figure $\mathbf{1}$.

As shown in Figure 1, the aluminosilicate framework of zeolite $\mathrm{NaA}$ is generated by placing truncated octahedrons (b-cage) at eight corners of a cube and each edge of the cube is formed by joining two b-cages by a D4R linkage. Each b-cage encloses a cavity with a free diameter of $0.66 \mathrm{~nm}$ and each unit cell encloses a larger cavity (a-cage) enclosing a free diameter of $1.14 \mathrm{~nm}$. There are two interconnecting, three-dimensional channels in zeolite $\mathrm{NaA}$ : (i) connected acages, $1.14 \mathrm{~nm}$ in diameter, separated by $0.42 \mathrm{~nm}$ apertures, (ii) b-cages, alternating with a-cages separated by $0.22 \mathrm{~nm}$ apertures (Sanaa 2015). Thus, molecules smaller than $0.42 \mathrm{~nm}$ in diameter can diffuse easily through the nanopores of the zeolite. In addition, position of sodium ions in unit cells is important since these ions act as the sites for water sorption and transport through the membrane. For a typical zeolite, a unit cell having the composition $\mathrm{Na}_{12} \mathrm{Al}_{12} \mathrm{Si}_{12} \mathrm{O}_{48} .27 \mathrm{H}_{2} \mathrm{O}$, eight (out of 12) sodium ions are located inside an a-cage and four ions are located in bcages. Transport of solvent species (mainly water) through the zeolite matrix comprises of three steps: (i) strong adsorption of the species into a cage from feed side, (ii) surface diffusion of the 
species from cage to cage and (iii) vaporization of the species to permeate side. Normally, any physical adsorption process includes both van der Waals dispersion-repulsion forces and electrostatic forces comprising of polarization, dipole and quadrupole interactions. However, since the zeolites have an ionic structure, the electrostatic forces become very large in adsorption of polar molecules like $\mathrm{H}_{2} \mathrm{O}$. This effect is manifested in the fact that heat of adsorption of water into zeolitic adsorbents is unusually high (25-30 $\mathrm{kcal} / \mathrm{mole}$ ) (Benito et al. 2007).

\section{EXPERIMENTAL}

\section{Saline Wastewater}

Its wastewater contains low concentrations of UDMH ( $<2$ wt. \%) besides impurities such as sodium chloride salt (8\%) and water (>90\%).

\section{Support Preparation}

In ceramic membranes, thin dense layers are usually deposited over porous supports. The porous supports provide mechanical strength for the thin selective layers. Porous supports can be made from alumina, cordierite, mullite, silica, spinel, zirconia, other refractory oxides and various oxide mixtures, carbon, sintered metals and silicon carbide. In this research, mullite supports have been prepared from kaolin clay. Kaolin is thermally converted to mullite via high temperature calcinations. The reaction takes place when kaolin is utilized as the sole source of silica and alumina. The reaction can be represented by the following equation:
$3\left(\mathrm{Al}_{2} \mathrm{O}_{3} \cdot 2 \mathrm{SiO}_{2}\right) \rightarrow 3 \mathrm{Al}_{2} \mathrm{O}_{3} \cdot 2 \mathrm{SiO}_{2}+4 \mathrm{SiO}_{2}$

Free silica $\left(4 \mathrm{SiO}_{2}\right)$ is generated as a result of this conversion. The free silica has been leached out and then porous mullite bodies have been prepared. Mullite has several distinct advantages over other materials. Since kaolin is heated to high temperatures to achieve the mullite conversion reaction, strong intercrystalline bonds between mullite crystals are formed and this results in excellent strength and attrition. Leaching time depends on several factors including:

1) the quantity of free silica to be removed,

2) the porosity of body prior to leaching,

3) the concentration of leaching solution and

4) temperature.

Kaolin (SL-KAD grade) has been supplied by WBB cooperation, England. Analysis of the kaolin is listed in Table 2. Cylindrical shaped (tubular) bodies (ID: 10 $\mathrm{mm}, \mathrm{OD}: 14 \mathrm{~mm}$ and $\mathrm{L}: 15 \mathrm{~cm}$ ) have been conveniently made by extruding a mixture of about $75-67 \%$ kaolin and $25-33 \%$ distilled water. Suitable calcinations temperatures and periods are those at which kaolin converts to mullite and free silica. Good results have been achieved by calcining for about $3 \mathrm{~h}$ at temperatures of about $1250^{\circ} \mathrm{C}$ (Speronello 1986).

Free silica has been removed from the calcined bodies after leaching by strong alkali solutions. Removal of the silica causes mesoporous tubular supports to be made with very high porosity. Free silica removal has been carried out using aqueous solutions containing $20 \%$ by 
Table 2. Analysis of Kaolin Clay

\begin{tabular}{|c|c|c|c|}
\hline Component & Percent (\%) & Phases & Percent (\%) \\
\hline $\mathrm{SiO}_{2}$ & 51.9 & Kaolinite & 79 \\
\hline $\mathrm{TiO}_{2}$ & 0.1 & Illite & 8 \\
\hline $\mathrm{Al}_{2} \mathrm{O}_{3}$ & 34.1 & Quartz & 10 \\
\hline $\mathrm{Fe}_{2} \mathrm{O}_{3}$ & 1.4 & Feldspar & 3 \\
\hline $\mathrm{K}_{2} \mathrm{O}$ & 0.8 & \multirow{4}{*}{ Total } & \multirow{4}{*}{100} \\
\hline $\mathrm{Na}_{2} \mathrm{O}$ & 0.1 & & \\
\hline L.O.I & 11.6 & & \\
\hline Total & 100 & & \\
\hline
\end{tabular}

weight $\mathrm{NaOH}$ at a temperature of $80{ }^{\circ} \mathrm{C}$ for $5 \mathrm{~h}$. Supports have been rinsed using a lot of hot distilled water for a long time in order to remove the all remaining $\mathrm{NaOH}$. Porosity of the supports before leaching is $24.3 \%$, while after treatment it increases to $49 \%$. Flux of the supports before and after free silica removal at 1 bar and $20{ }^{\circ} \mathrm{C}$ is 6 $\mathrm{kg} / \mathrm{m}^{2} \mathrm{~h}$ and $10 \mathrm{~kg} / \mathrm{m}^{2} \mathrm{~h}$, respectively. Porosity of the supports has been measured by water absorption method. Phase identification has been performed by X-ray diffractometry with $\mathrm{CuK}_{\alpha}$ radiation.

\section{Zeolite Membrane Synthesis}

\section{Coating of The Support with Seeds}

Porous mullite tubes (homemade) as describe above have been used as the support. The external surface of the supports have been polished with 600 grit-sand papers, and then the support has been washed and cleaned with distilled water in a microwave heater for $5 \mathrm{~min}$ to remove loose particles created during polishing. Then, supports have been dried at $100{ }^{\circ} \mathrm{C}$ for $3 \mathrm{~h}$.

In order to form a thin and uniform zeolite membrane on the mullite support, the nucleation seeds should be small and uniform in size. In order to inhibit the formation of zeolites into the support pores, the seeds should not penetrate into the pores. The high purity nucleation seeds have been synthesized by hydrothermal method. Size of the seeds is about $2 \mu \mathrm{m}$. The seeds should be dispersed homogeneously on the support surface and the amount of seeds on the support surface should not be too much. Otherwise, the synthesized zeolite membrane is heterogeneous or too thick.

The seeded supports have been prepared by dipping the mullite supports in an $8 \% \mathrm{NaA}$ zeolite suspension in a single step. The $8 \% \mathrm{NaA}$ zeolite suspension has been prepared by mixing 8 $\mathrm{g} \mathrm{NaA}$ zeolite in $92 \mathrm{ml}$ distilled water. After dipping procedure, the supports have been dried at $100^{\circ} \mathrm{C}$ for $3 \mathrm{~h}$.

\section{NaA Zeolite Synthesis}

In ceramic membranes, thin dense layers are usually deposited over porous supports. The porous supports provide mechanical strength for the thin selective layers. Porous supports can be made from alumina, cordierite, mullite, silica, spinel, zirconium, other refractory oxides and various oxide mixtures, carbon, sintered 


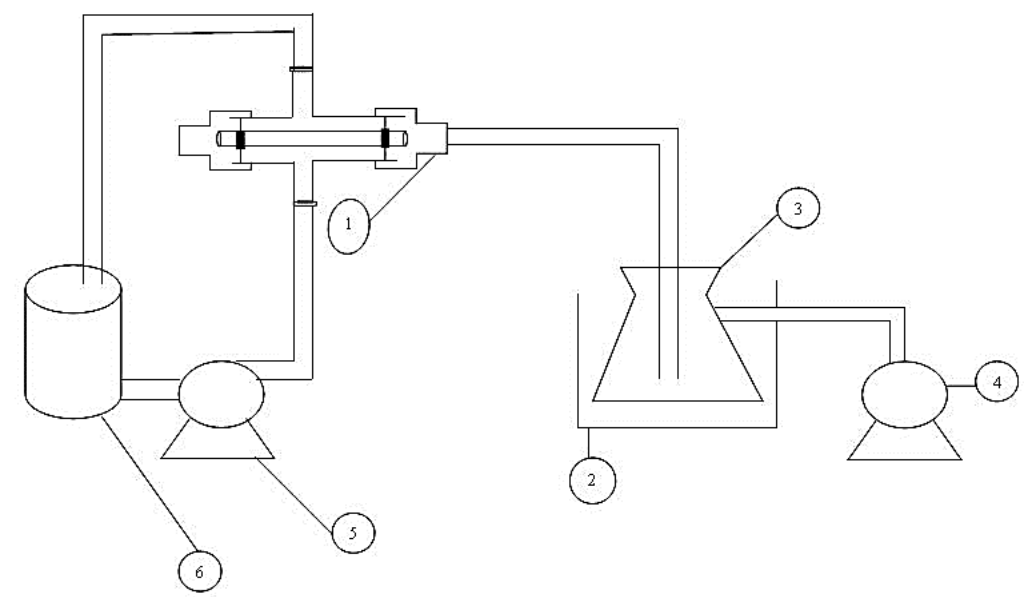

Fig. 2: PV Setup; 1- feed container and PV cell 2- liquid nitrogen trap 3-permeate container 4- three-stage vacuum pump 5-centrifuge pump 6- feed tank

metals and silicon carbide. NaA zeolite membrane was grown hydrothermally on the outer surface of a porous tubular mullite support (14 $\mathrm{mm}$ outer diameter, 10 $\mathrm{mm}$ inner diameter, $10 \mathrm{~cm}$ length). The hydrothermal synthesis of $\mathrm{NaA}$ zeolite membrane was performed as follows. An aluminate solution was prepared by dissolving sodium hydroxide and aluminium hydroxide in distilled water. A silicate solution was prepared by dissolving sodium silicate in distilled water. The aluminate solution was added to the silicate solution and the resulting mixture was stirred vigorously, producing a homogeneous gel. The molar composition of the resulting gel was $\mathrm{SiO}_{2} / \mathrm{Al}_{2} \mathrm{O}_{3}=1.926$, $\mathrm{Na}_{2} \mathrm{O} / \mathrm{Al}_{2} \mathrm{O}_{3}=3.165$ and $\mathrm{H}_{2} \mathrm{O} / \mathrm{Al}_{2} \mathrm{O}_{3}=128$ (Sonia et al.2009). The porous support coated with crystal seeds of $\mathrm{NaA}$ zeolite was dipped in the gel. After hydrothermal treatment at $100^{\circ} \mathrm{C}$ for $3 \mathrm{~h}$, the support was taken out, washed by water and dried at reduced pressure. The treated tube was analyzed by X-ray diffraction (XRD) for making sure about the formation of zeolite thin layer on its surface. The surface morphology of the membrane was also observed by scanning electron microscopy (SEM).

\section{Membrane Test Experiments}

A PV experimental set up was used to evaluate successful fabrication of $\mathrm{NaA}$ zeolite membranes. PV experiments were carried out using a PV apparatus. Feed solution (total dissolve solid (TDS) equal to $10 \mathrm{gr} / \mathrm{l}$ or $10000 \mathrm{ppm}$ and 2\%UDMH), preheated to a constant temperature, and was introduced to the outer side of the zeolite membrane in the PV cell. The downstream pressure was maintained at $133 \mathrm{~Pa}$ throughout the operation. The zeolite membranes were used for desalination of water mixtures. The experiments have been carried out at a temperature of $30^{\circ} \mathrm{C}$ and a pressure of 1.5 mbara at the permeate side, within a period of 30-60 min.

The permeate side has been connected to a liquid nitrogen trap via a hose to condense the permeate (vapor). The pervaporation setup is presented in Figure 2. Any change of feed concentration due 


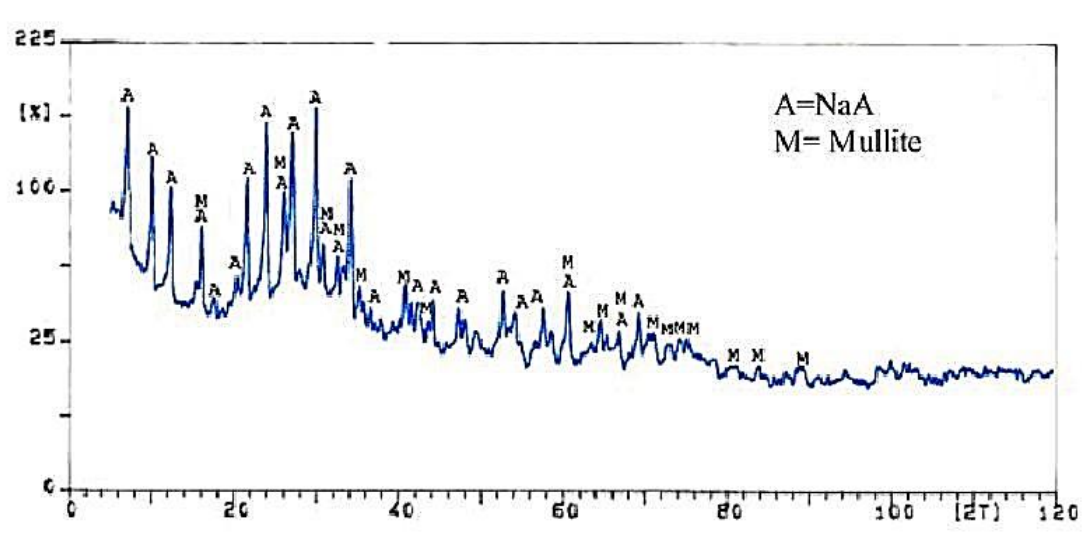

Fig. 3: XRD Patterns The Membrane

to permeation is negligible because the amount of permeate is small ( $\max 2 \mathrm{ml}$ ) compared to total feed volume in the system (0.5 lit). A three stage diaphragm vacuum pump (vacuubrand, $\mathrm{GMBH}$, Germany) has been employed to evacuated the permeate side of the membrane to a pressure of approximately 1.5 mbara while the feed side has been kept at room pressure. Permeate concentrations were measured by conductivity. In addition, Permeate concentrations have been measured by a GC (TCD detector, Varian 3400). Performance of PV is usually evaluated by total flux $\left(\mathrm{kg} / \mathrm{m}^{2} \mathrm{~h}\right)$ and separation factor (dimensionless). Separation factor of any organic aqueous solution can be calculated from the following equation:

separation factor $(\alpha)=\frac{\left[\frac{X_{\mathrm{H}_{2} \mathrm{O}}}{X_{\text {organic }}}\right]_{\text {permeate }}}{\left[\frac{X_{\mathrm{H}_{2} \mathrm{O}}}{X_{\text {organic }}}\right]_{\text {feed }}}$

Where $X_{\mathrm{H}_{2} \mathrm{O}}$ and $X_{\text {organic }}$ are weight fractions of water and organic compound, respectively.

\section{RESULTS AND DISCUSSION}

The phases Mullite, Cristobalite and $\mathrm{SiO}_{2}$ identification was performed by XRD (Philips PW1710, Philips Co., Netherlands) with $\mathrm{CuK} \alpha$ radiation. Morphology of the support and the membrane was examined by SEM (JEM-1200 or JEM-5600LV equipped with an Oxford ISIS-300 X-ray disperse spectroscopy (EDS)). Figure $\mathbf{3}$ shows XRD pattern of the mullite support and $\mathrm{NaA}$ zeolite membrane. The XRD pattern of $\mathrm{NaA}$ zeolite membrane confirms that zeolite $\mathrm{NaA}$ crystals were formed.

Figure 4 shows SEM photograph of the mullite support preparation by kaolin source. Figure $\mathbf{5}$ shows SEM photographs of the $\mathrm{NaA}$ zeolite membrane. Porous structure of the support and thin layer of the membrane can be easily observed.

Separation performance of the $\mathrm{NaA}$ membranes was evaluated using pervaporation of saline wastewater. As shown in Table 3, the membranes showed high water selectivity in the saline wastewater. The separation mechanism of the perfect $\mathrm{NaA}$ zeolite membranes is the size exclusion of hydrated ions, which have 


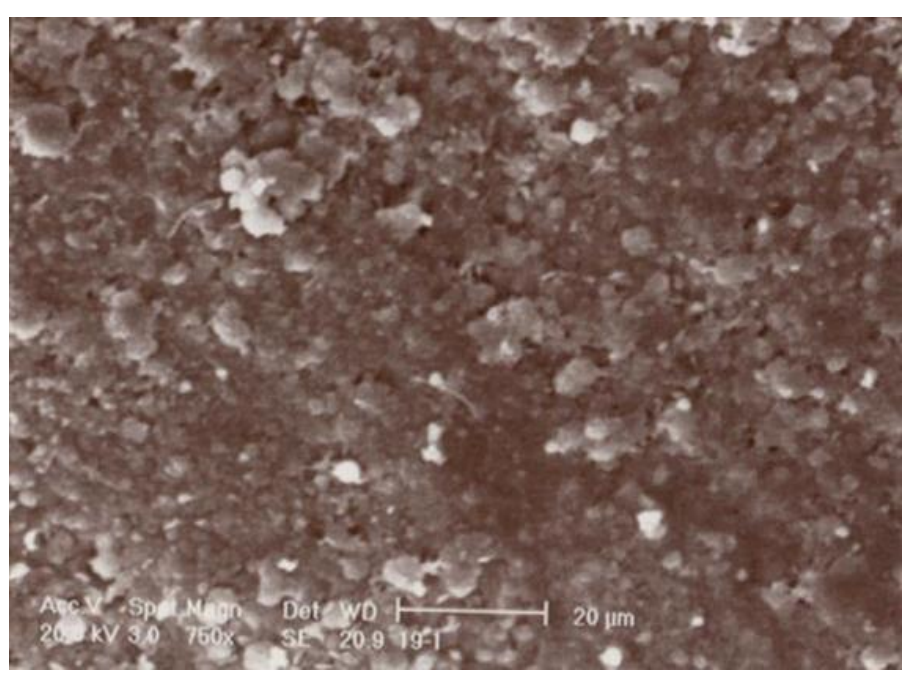

Fig. 4: SEM Micrograph of The Support
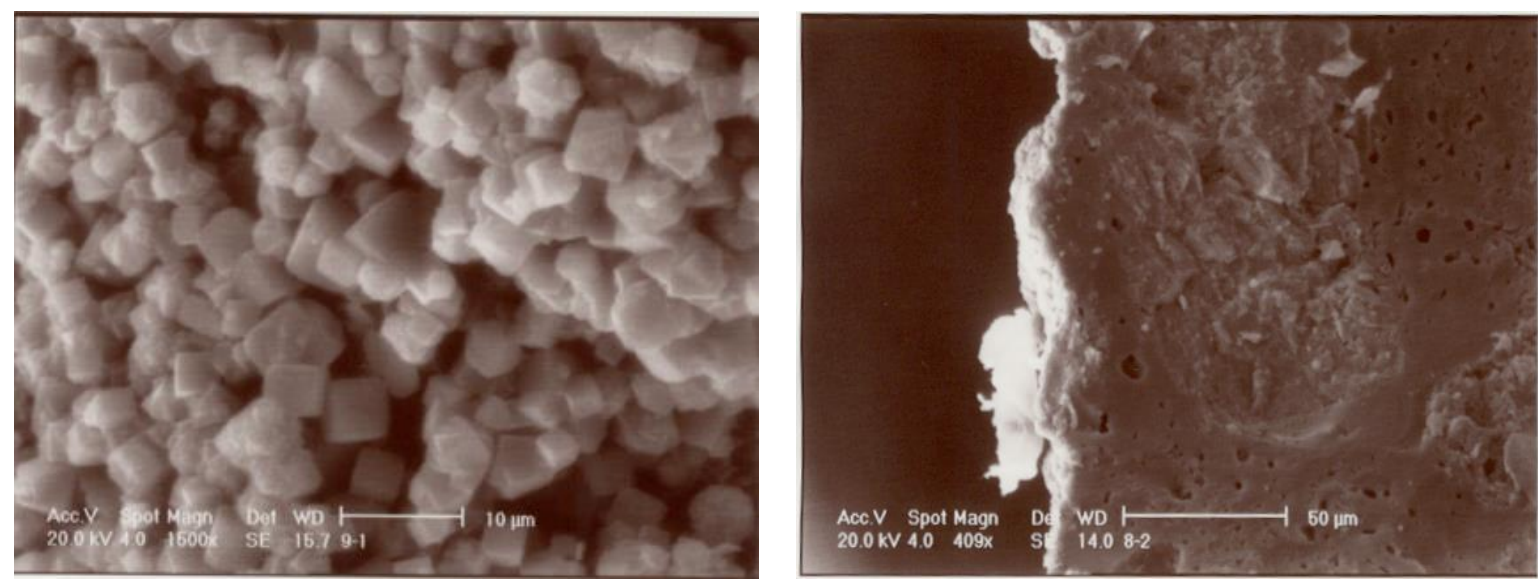

Fig. 5: SEM Micrograph of The Membrane on Support

Table 3. Flux and separation factor of the membranes

\begin{tabular}{ccccc}
\hline \multicolumn{2}{c}{ Feed } & \multicolumn{3}{c}{ Product } \\
$\begin{array}{c}\text { Organic pollution } \\
(\%)\end{array}$ & $\mathrm{NaCl}(\%)$ & $\left.\begin{array}{c}\text { Conductivity } \\
\left(\frac{\mu s}{\mathrm{~cm}}\right)\end{array}\right)$ at $25 \mathrm{C}$ & $\begin{array}{c}\text { Flux } \\
\mathrm{kg} / \mathrm{m}^{2} . \mathrm{h}\end{array}$ & $\begin{array}{c}\text { Separation } \\
\text { factor }\end{array}$ \\
\hline 2 & 8 & 4 & 1.75 & $>10000$ \\
\hline
\end{tabular}

kinetic sizes significantly larger than the aperture of the $\mathrm{NaA}$ zeolite. The Conductivity of permeate was $3 \frac{\mu s}{\mathrm{~cm}}$ (Conductivity of Distillated water equal to $\left.1.7 \frac{\mu \mathrm{s}}{\mathrm{cm}}\right)$. Results of PV test with NaA zeolite membrane to measure water fluxes in variable condition are presented in Figure

6.

\section{Operating Conditions}

The transmembrane pressure is adjusted between 1 and 3 bar. The feed temperature is varied between 20 and 60 ${ }^{\circ} \mathrm{C}$ by means of a small heat exchanger employed into the feed tank. Feed rate is varied between 0.5 and 3 lit/min by means of centrifuge pump and recycle line. 


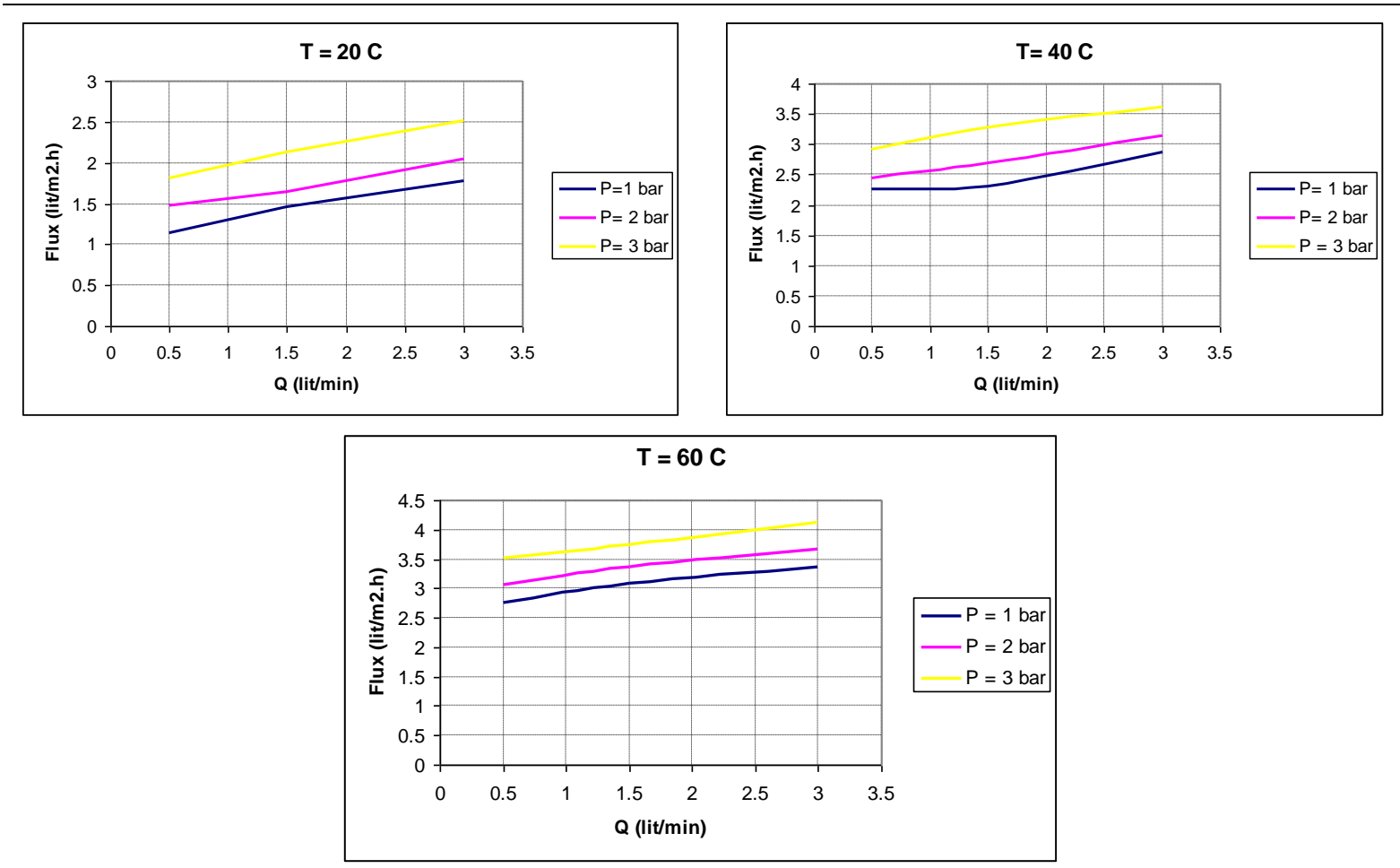

Fig. 6: PV Results by NaA Zeolite Membrane

Permeate collected in a sample bottle is measured. The outlet flow of the cell can be led out of the system or returned to the tank. A shown in figure 6 , effect of feed rate on water flux were measured at constant temperature $\left(20,40\right.$ and $\left.60^{\circ} \mathrm{C}\right)$ and constant pressure (1, 2 and 3 bar). Increasing feed rate increases (enhances) the permeate flux. At the optimum operating rate, permeate flux is so high. Figure 6 shows the optimum operating feed rate is $3 \mathrm{lit} / \mathrm{min}$. As shown, increasing pressure increases the permeate flux. Increasing rate increases turbulency and hydrodynamic effects cause to increasing water flux. As seen, the optimum operating transmembrane pressure is 3 bar. Temperature is known as a main parameter. Increasing temperature causes an increase in viscosity reduction. Figure 6 shows the experimental data for the flux as a function of temperature. As seen, the flux increases almost linearly with temperature. According to the results, it can be said the optimum operating temperature is $60^{\circ} \mathrm{C}$. Thus, the higher temperature the better result.

\section{CONCLUSION}

Zeolite membranes have great potential for applications in treatment of saline wastewater. Increasing pressure, feed rate and temperature increases the flux linearly. It is expected that even significantly higher fluxes, can be achieved at higher pressures, rates and temperatures. The study verified the application of membrane technology in the treatment of saline wastewater and it 
illustrated that the $\mathrm{NaA}$ zeolite membrane can be used as further concentration process of saline wastewater. Overall, the zeolite membrane showed excellent chemical resilience and produced a desalinated product suitable for reuse applications. The NaA zeolite membranes not only can separate water from organic molecules, but also are also capable of removing ions from aqueous solutions. The pervaporation studies with synthesized membranes demonstrated that the excellent properties of these membranes make them good candidates for concentration of hazardous wastewaters and also different ionic solutions. The results of this work can be used for developing a new method for removal of organic pollution and salts from water.

\section{REFERENCES}

1. Colomer, M. (2006). Nanoporous anatase ceramic membranes as fastproton-conducting materials. Journal of the European Ceramic Society, 26, 1231-1236.

2. Almutairi, L. (2015). Intensification of ammonia removal from wastewater in biologically active zeolitic ion exchange columns, Journal of Environmental Management, 160, 128138.

3. Premakshi, K., and Ramesh, M. (2015). Modification of crosslinked chitosan membrane using $\mathrm{NaY}$ zeolite for pervaporation separation of waterisopropanol mixtures, Chemical Engineering Research and Design, 94, 32-43.
4. Zhu, D., and Myat, G. (2015). Application of robust MFI-type zeolite membrane for desalination of saline wastewater. Journal of Membrane Science, 475, 167-174.

5. Malekpour, M.and Millani, M. (2008). Synthesis and characterization of a $\mathrm{NaA}$ zeolite membrane and its applications for desalination of radioactive solutions. Desalination, 225, 199-208.

6. Gazagnes, S. and Cerneaux, M. and Persin, E. and Prouzet, A. (2007). Desalination of sodium chloride solutions and seawater with hydrophobic ceramic membranes. Desalination, 217, 260-266.

7. Basu, S. and Mukherjee, A. (2015). Integrated treatment of molasses distillery wastewater using microfiltration (MF). Journal of Environmental Management, 158, 5560.

8. Sanaa, J. (2015). Recent improvements in oily wastewater treatment: Progress, challenges, and future opportunities. Journal of Environmental Sciences, 37, 15-37.

9. Benito, M.J. and Pena, M.A. (2007). Development of a new high porosity ceramic membrane for the treatment of bilge water. Desalination, 214, 91101.

10. Speronello, K. (1986). Porous mullite. U.S. Patent No., 4601997.

11. Sonia, A. and Gascn, J. C. (2009). Continuous synthesis of $\mathrm{NaA}$ zeolite membranes. Microporous and Mesoporous Materials, 120, 170-176. 